\title{
Anti-Müllerian hormone: correlation with testosterone and oligo- or amenorrhoea in female adolescence in a population-based cohort study
}

\author{
P.Pinola' ', L.C. Morin-Papunen I,*, A. Bloigu' ${ }^{2}$, K. Puukka ${ }^{3}$, A. Ruokonen ${ }^{3}$, \\ M.-R. Järvelin 2,4,5,6,7, S. Franks ${ }^{8}$, J.S. Tapanainen 1,9, and H. Lashen ${ }^{10}$ \\ 'Department of Obstetrics and Gynaecology, Oulu University Hospital, University of Oulu and Medical Research Center Oulu, Oulu, Finland \\ ${ }^{2}$ Department of Children and Young People and Families, National Institute for Health and Welfare, Aapistie I, Box 310 , FI-90 IOI Oulu, Finland \\ ${ }^{3}$ NordLab Oulu, Oulu University Hospital and Department of Clinical Chemistry, University of Oulu, Oulu, Finland ${ }^{4}$ Department of Epidemiology \\ and Biostatistics, MRC Health Protection Agency (HPA) Centre for Environment and Health, School of Public Health, Imperial College London, \\ London, UK ${ }^{5}$ Institute of Health Sciences, University of Oulu, PO Box 5000, FI-900I 4 Oulu, Finland ${ }^{6}$ Biocenter Oulu, University of Oulu, \\ Aapistie 5A, PO Box 5000, FI-900I 4 Oulu, Finland 'Unit of Primary Care, Oulu University Hospital, Kajaanintie 50, PO Box 20, FI-90220 Oulu, \\ 90029 OYS, Finland ${ }^{8}$ Institute of Reproductive and Developmental Biology, Imperial College London, London, UK ${ }^{9}$ Department of Obstetrics \\ and Gynaecology, University of Helsinki and Helsinki University Central Hospital, Helsinki, Finland ${ }^{10}$ Department of Human Metabolism, \\ University of Sheffield, Jessop Wing, Sheffield, UK \\ *Correspondence address. Tel: +358-83 I54I09; Fax: +358-83 I54I30; E-mail: Imp@cc.oulu.fi
}

Submitted on February 3, 20 I 4; resubmitted on June I7, 20 I 4; accepted on June 26, 2014

STUDY QUESTIONS: Can serum anti-Müllerian hormone (AMH) levels measured in female adolescents predict polycystic ovary syndrome (PCOS)-associated features in adolescence and early adulthood?

SUMMARY ANSWER: AMH levels associated well with PCOS-associated features (such as testosterone levels and oligoamenorrhoea) in adolescence, but was not an ideal marker to predict PCOS-associated features in early adulthood.

WHAT IS KNOWN ALREADY: Several studies have reported that there is a strong correlation between antral follicle count and serum AMH levels and that women with PCOS/PCO have significantly higher serum AMH levels than women with normal ovaries. Other studies have reported an association between $\mathrm{AMH}$ serum levels and hyperandrogenism in adolescence, but none has prospectively assessed $\mathrm{AMH}$ as a risk predictor for developing features of PCOS during adulthood.

STUDY DESIGN, SIZE, DURATION: A subset of 400 girls was selected from the prospective population-based Northern Finland Birth Cohort $1986(n=4567$ at age 16 and $n=4503$ at age 26). The population has been followed from 1986 to the present.

PARTICIPANTS/MATERIAL, SETTING, METHODS: At age I 6, 400 girls ( 100 from each testosterone quartile: 50 with oligo- or amenorrhoea and 50 with a normal menstrual cycle) were selected at random from the cohort for AMH measurement. Metabolic parameters were also assessed at age 16 in all participants. Postal questionnaires enquired about oligo- or amenorrhoea, hirsutism, contraceptive use and reproductive health at ages 16 and 26 .

MAIN RESULTS AND ROLE OF CHANCE: There was a significant correlation between AMH and testosterone at age I6 $(r=0.36$, $P<0.001)$. AMH levels at age 16 were significantly higher among girls with oligo- or amenorrhoea compared with girls with normal menstrual cycles (35.9 pmol/I [95\% Cl: 33.2;38.6] versus 27.7 pmol/I [95\% Cl: 25.0;30.4], P<0.00 I). AMH at age I6 was higher in girls who developed hirsutism at age 26 compared with the non-hirsute group (3I.4 pmol/I [ $95 \% \mathrm{Cl} 27.1 ; 36.5]$ versus $25.8 \mathrm{pmol} / \mathrm{I}[95 \% \mathrm{Cl} 23.3 ; 28.6], P=0.036)$. $\mathrm{AMH}$ at age 16 was also higher in women with PCOS at age 26 compared with the non-PCOS subjects (38.I pmol/I [95\% Cl 29.1;48.4] versus $30.2 \mathrm{pmol} / \mathrm{I}[95 \% \mathrm{Cl} 27.9 ; 32.4], P=0.044$ ). The sensitivity and specificity of the AMH (cut-off 22.5 pmol/I) for predicting PCOS at age 26 was 85.7 and $37.5 \%$, respectively. The addition of testosterone did not significantly improve the accuracy of the test. There was no significant correlation between $\mathrm{AMH}$ levels and metabolic indices at age 16.

IMPLICATIONS, REASONS FOR CAUTION: AMH is related to oligo- or amenorrhoea in adolescence, but it is not a good marker for metabolic factors. The relatively low rate of participation in the questionnaire at age 26 may also have affected the results. AMH was measured in a

(C) The Author 2014. Published by Oxford University Press on behalf of the European Society of Human Reproduction and Embryology.

This is an Open Access article distributed under the terms of the Creative Commons Attribution License (http://creativecommons.org/licenses/by/4.0/), which permits unrestricted reuse, distribution, and reproduction in any medium, provided the original work is properly cited. 
subset of the whole cohort. AMH measurement is lacking international standardization and therefore the concentrations and cut-off points are method dependent.

WIDER IMPLICATIONS FOR THE FINDINGS: Using a high enough cut-off value of AMH to predict which adolescents are likely to develop PCOS in adulthood could help to manage the condition from an early age due to a good sensitivity. However, because of its low specificity, it is not an ideal diagnostic marker, and its routine use in clinical practice cannot, at present, be recommended.

STUDY FUNDINGS AND COMPETING INTERESTS: The study was funded by a grant from Wellcome Trust (089549/Z/09/Z) to H.L., S.F. and M.-R.J. Study funding was also received from Oulu University Hospital Research Funds, Sigrid Juselius Foundation and the Academy of Finland. None of the authors have any competing interest to declare.

Key words: AMH / female adolescence / PCOS / oligo- or amenorrhoea / testosterone

\section{Introduction}

Anti-Müllerian hormone (AMH) plays a central role in sexual differentiation by inducing the regression of the Müllerian ducts in male fetuses. In females, AMH is produced in the granulosa cells of the human ovary after mid-gestation (Vigier et al., 1984; Rajpert-De Meyts et al., 1999; Kuiri-Hänninen et al., 201 I). AMH is expressed in granulosa cells of growing follicles up to the antral stage, suggesting an important role in early ovarian folliculogenesis (Weenen et al., 2004; Stubbs et al., 2005). AMH is able to inhibit the initiation of primordial follicle growth (Durlinger et al., 2002) and may also decrease the sensitivity of antral follicles to follicle-stimulating hormone (FSH) (Durlinger et al., 1999, 2002; Gruijters et al., 2003). Testosterone has been shown to lower AMH expression in the mammalian ovary in vitro (Crisosto et al., 2009). In humans, however, the association between androgens and $\mathrm{AMH}$ remains uncertain, and its exact function in follicular recruitment and long-term effects is not well understood.

Polycystic ovary syndrome (PCOS) is the most common endocrine disorder in women, producing symptoms of hyperandrogenism, oligoor amenorrhoea and polycystic ovaries (PCO) (Franks 1995; Ehrmann 2005). Serum AMH levels and the ovarian antral follicle count (AFC) correlate closely both in healthy subjects and in women with PCOS (Pigny et al., 2003, 2006; Weenen et al., 2004). In PCOS, serum AMH correlates positively with serum concentrations of testosterone $(T)$ and negatively with age (Piltonen et al., 2005). Furthermore, women with higher serum levels of $\mathrm{AMH}$ and $\mathrm{T}$ have longer menstrual cycles compared with those with lower levels (Kristensen et al., 20I2). In line with these observations, in non-hirsute girls with oligo-amenorrhoea (OA), the levels of $\mathrm{AMH}$ are similar to those in the PCOS population but higher than in girls with normal cycles (Hart et al., 20I0a,b; Park et al., 20I0a,b). AMH has been reported to be not associated with metabolic risks in adolescence and in early adulthood (Lin et al., 20 I I; Anderson et al., 20I3), but contradictory results have been published in adult female populations (Nardo et al., 2009; Park et al., 20 I0a,b; Skalba et al., 20I I).

The use of the measurement of serum AMH serum levels as a diagnostic tool for PCOS has been recently under debate (Dewailly et al., 20I I; Eilertsen et al., 2012; lliodromiti et al., 2013). Women with PCOS have higher concentrations of $\mathrm{AMH}$, and accordingly, $\mathrm{AMH}$ correlates with the AFC. Thus, AMH has been proposed to be a substitute for AFC in the diagnosis of PCOS (Pigny et al., 2006; Dewailly et al., 20I I; Eilertsen et al., 20I2). AMH has also been reported to correlate with other symptoms of PCOS, such as hyperandrogenism and oligoamenorrhoea (Pigny et al., 2003; Laven et al., 2004; Piltonen et al., 2005; Nardo et al., 2009;
Li et al., 20II; Skalba et al., 20I I). There are, however, no follow-up studies on the subject of AMH as a possible predictor of PCOS and its typical symptoms (oligo- or amenorrhoea, hirsutism and hyperandrogenism) in later life.

PCOS is also associated with increased metabolic risks in later life (Legro 2002; Solomon et al., 2002; Nisenblat and Norman 2009). For clinicians to be able to prevent adverse health events in PCOS, predicting the syndrome early in life is important. We have recently reported that oligo- or amenorrhoea at the time of adolescence is associated with hyperandrogenaemia and may represent a risk factor for the development of PCOS in adulthood. Furthermore, we have also reported an association between obesity, hyperandrogenaemia and metabolic risks among I6-year-old adolescent girls (Pinola et al., 20I2). We hypothesize that $\mathrm{AMH}$ could be used as an early marker for reproductive and metabolic future risks linked to PCOS to allow early preventive actions such as lifestyle changes.

The main aim of the present study was to elucidate the relationship between serum $\mathrm{AMH}$ and testosterone levels, oligo- or amenorrhoea, and metabolic and cardiovascular markers at the age of 16 , and to evaluate whether $\mathrm{AMH}$ can be used as a marker for predicting future cycle irregularities, hirsutism and diagnosis of PCOS.

\section{Materials and Methods}

\section{Study Population}

The study population was a subset of 400 subjects, from the Northern Finland Birth Cohort 1986 (NFBC-86), selected to be assayed for serum AMH.

The prospective NFBC-86, comprised 9362 mothers and their 9479 births (9432 children born alive), who had an expected date of birth between I July 1985 and 30 June 1986, drawn from the northernmost part of Finland. In 200 I-2002, when the children were 16 years old, the adolescents and their parents received postal questionnaires. Of the female adolescents $(n=4567)$ then living in Finland, either in the original catchment area or elsewhere; $80.3 \%$ answered the questionnaire and $74 \%$ underwent clinical examination (i.e. anthropometric measurements) and gave fasting blood samples. After excluding twins and triplets, pregnant girls $(n=20)$, oral contraceptive users and users of other forms of hormonal contraception and treatment $(n=377)$, and subjects with incomplete data $(n=824)$, 2448 singleton females remained eligible.

The selection of the study population for the measurement for serum AMH was completed among the subjects who answered both questionnaires at ages 16 and 26 . The study population was split into testosterone quartiles and the final group of study subjects ( 100 subjects from each testosterone 
quartile: 50 subjects with reported oligo- or amenorrhoea and 50 with normal menstrual cycles) were randomly selected from each quartile using a validated statistical method (SPSS software).

The questionnaire included a question about the regularity and length of the menstrual cycle: "Is your menstrual cycle (the interval from the beginning of one menstrual period to the beginning of the next period) often (more than twice a year) longer than 35 days?'. In addition, the girls answered to the following question: 'If you are using oral contraceptives, how long was your menstrual cycle during the year before you started any oral contraceptives?'. The girls who had a menstrual cycle often (more than twice a year) longer than 35 days at the time of the questionnaire and/or before the use of oral contraceptives were considered to be suffering from oligo- or amenorrhoea.

In 2012, when the subjects were 26 years old, a new questionnaire enquiring about the menstrual cycles was posted to all the girls who participated in the previous survey at age 16. This questionnaire included the same question on oligo- or amenorrhoea as at age 16 . Further, the incidence of hirsutism was also self-assessed using a modified Ferriman and Gallwey (F\&G) score sheet. The total response rate for 26 -year-old questionnaire was $50.4 \%$. The subjects of the subpopulation used in the present study had answered both questionnaires. The diagnosis of PCOS was enquired from the questionnaire (answer to the question: 'Have you been diagnosed for PCOS by a physician?'). Additionally, women with both hirsutism and oligo- or amenorrhoea according to the questionnaire at age 26 were considered to have PCOS according to both the $\mathrm{NIH}$ and the Rotterdam criteria (Rotterdam ESHRE/ASRM-Sponsored PCOS consensus workshop group, 2004).

The Ethics Committee of the Northern Ostrobothnia Hospital District approved this study and informed consent was obtained from all subjects.

\section{Assays}

At age 16, serum samples were assayed for testosterone (T) using Agilent triple quadrupole 6410 LC/MS equipment with an electrospray ionization source operating in positive-ion mode (Agilent Technologies, Wilmington, DE, USA). Multiple reaction monitoring was used to quantify testosterone by using $\mathrm{d} 3$-testosterone. The intra-assay $\mathrm{CV}$ s of the method were $5.3,1.6$ and $1.2 \%$ for testosterone at $0.6,6.6$ and $27.7 \mathrm{nmol} / \mathrm{l}$, respectively. The inter-assay CVs were 5.3, 4.2 and $1.0 \%$ for the respective concentrations. In an adult female population, an upper limit of $2.3 \mathrm{nmol} / \mathrm{I}$ is considered as the upper normal limit in our laboratory.

Plasma glucose, total cholesterol, high-density lipoprotein cholesterol (HDL-cholesterol), low-density lipoprotein cholesterol (LDL-cholesterol) and triglycerides, fasting insulin, high sensitivity C-reactive protein (hsCRP) and sex hormone binding globulin were all assayed as previously described (Pinola et al., 20I2). To quantify the degree of insulin sensitivity, homeostasis model assessment (HOMA) values were calculated using the validated calculator available at http://www.dtu.ox.ac.uk.

Serum AMH concentration was assayed in the stored samples by $\mathrm{AMH}$ Gen II enzyme linked immunosorbent assay (ELISA, Beckman Coulter, Inc., 250 S. Kraemer Blvd. Brea, CA 9282 I USA) as previously described (Kumar et al., 20 I0; Wallace et al., 20I I). Intra- and inter-assay coefficients of variation were 4.6 and $8.0 \%$ at $0.05 \mathrm{ng} / \mathrm{ml}$ concentration; I $\mathrm{ng} / \mathrm{ml}$ of AMH converts to $7.14 \mathrm{pmol} / \mathrm{l}$.

\section{Data analysis}

The study population of 400 girls was constituted from four equal groups (quartiles) according to their testosterone levels. The AMH levels were compared between the four quartiles. In the whole study population and within each testosterone quartile, a correlation analysis was carried out between $\mathrm{AMH}$ and incidence of irregular anovulatory cycles/oligo-amenorrhea and hirsutism based on the F\&G scores obtained at age 26 . Further, in the whole population and in each testosterone quartile $\mathrm{AMH}$ was correlated with metabolic and cardiovascular risk markers (waist-hip ratio, serum fasting insulin, plasma fasting glucose, total cholesterol, HDL-cholesterol, LDL-cholesterol, triglycerides, hsCRP and HOMA for insulin sensitivity), adjusting for testosterone and BMI.

\section{Statistical methods}

The distribution of AMH was skewed; therefore it was logarithmically transformed to achieve normality in the analyses of hirsutism. The Chi square test was used to compare categorical variables between the testosterone quartiles. The confidence intervals for proportions were calculated using CIA computer program (Gardner and Altman 1989). The potential trends in continuous variables across the testosterone quartiles were examined using the test for linear trend available in analysis of variance (ANOVA). In order to be able to adjust for confounding variables, ANOVA and analysis of covariance (ANCOVA) were adopted when comparing AMH levels between two groups. Correlations were tested using Pearson's correlation analysis. Partial correlation analysis was used to control for confounding variables. Bias-corrected and accelerated $95 \%$ confidence intervals of the correlation coefficients were calculated with 1000 bootstrap resamples. We constructed a receiver operating characteristic ( $\mathrm{ROC}$ ) curve with $\mathrm{AMH}$ and testosterone at age 16 for PCOS at age 26. The cut-off value of $\mathrm{AMH}$ and testosterone were selected to identify PCOS subjects, with the best sensitivity and specificity. Analyses were performed by using SPSS 18.0 software (SPSS, Inc., Chicago, IL, USA).

\section{Results}

The background characteristics of the study population are shown in the Table I. At age 16, the BMI was significantly increased towards greater testosterone quartile $(P$-value for trend $<0.00 \mathrm{I})$. Mean levels of testosterone in testosterone quartiles were I. 05 in the first, I. .46 in the second, $\mathrm{I} .83$ in the third and $2.49 \mathrm{nmol} / \mathrm{l}$ in the fourth quartile.

\section{AMH and testosterone}

There was a significant correlation between serum $\mathrm{AMH}$ and $\mathrm{T}$ at age 16 $[r=0.36,95 \%$ confidence interval $(95 \% \mathrm{Cl}) 0.24-0.47, P<0.00 \mathrm{I}]$. After dividing the study population into $T$ quartiles, the correlation was significant only in the highest $\mathrm{T}$ quartile $(r=0.33,95 \% \mathrm{Cl} 0.0 \mathrm{I}-0.56$, $P=0.00 \mathrm{I})$. These results were independent of BMI, WHR and age at menarche. AMH levels increased significantly from the lowest towards the highest T quartile ( $P$-value for trend $<0.00$ I, Fig. I).

\section{AMH and oligo- or amenorrhoea}

At age 16, the girls who reported oligo- or amenorrhoea $(n=200)$ had higher AMH levels compared with those reporting normal cycles $(n=$ 200) $[35.9 \mathrm{pmol} / \mathrm{l}(95 \% \mathrm{Cl}: 33.2 ; 38.6)$ versus $27.7 \mathrm{pmol} / \mathrm{l}(95 \% \mathrm{Cl}$ : 25.0; 30.45), $P<0.00 \mathrm{I}$ ], and adjustment for BMI, WHR or T did not change the results. Subjects with oligo- or amenorrhoea had higher serum AMH levels in the second, third and fourth T quartiles compared with those with regular menstrual cycles (Fig. 2). Serum AMH levels at age 16 did not differ significantly between women with oligo- or amenorrhoea and women without oligo- or amenorrhoea at age 26. However, within the highest testosterone quartile, the women with oligo- or amenorrhoea $(n=23)$ at age 26 had higher AMH levels at age 16, compared with women with normal menstrual cycles $(n=62)$ at age 26, after adjusting for $\mathrm{T}$ and $\mathrm{BMI}[45.5 \mathrm{pmol} / \mathrm{I}(95 \% \mathrm{Cl}$ : 36.0 ; $55 . \mathrm{I})$ versus $36 . \mathrm{I} \mathrm{pmol} / \mathrm{I}(95 \% \mathrm{Cl}: 30.3 ; 4 \mathrm{I} .9), P=0.04$ ]. 
Table I Background characteristics of the study population.

\begin{tabular}{|c|c|c|c|c|c|c|c|}
\hline \multirow{2}{*}{\multicolumn{2}{|c|}{$\begin{array}{l}\text { Characteristics of study } \\
\text { population }\end{array}$}} & \multirow{2}{*}{$\begin{array}{l}\text { Whole } \\
\text { population }\end{array}$} & \multicolumn{4}{|c|}{ Testosterone quartile } & \multirow[t]{2}{*}{$P$-value ${ }^{\text {e }}$} \\
\hline & & & Ist & 2nd & 3rd & 4th & \\
\hline $\begin{array}{l}\text { Socio-economic state } \\
16 \text { years }^{\mathrm{a}} \\
(N=370)\end{array}$ & $\begin{array}{l}\text { White collar } \\
\text { Blue collar } \\
\text { Worker } \\
\text { Other }\end{array}$ & $\begin{array}{l}21.9 \%(17.7 ; 26.1) \\
49.2 \%(44.1 ; 54.3) \\
17.0 \%(13.2 ; 20.9) \\
11.9 \%(8.6 ; 15.2)\end{array}$ & $\begin{array}{l}\text { I7.7\% (10.7; 26.8) } \\
53.1 \%(42.7 ; 63.4) \\
\text { I7.7\% (10.7; 26.8) } \\
\text { II.5\% (5.9; 19.6) }\end{array}$ & $\begin{array}{r}22.6 \%(14.6 ; 32.4) \\
43.0 \%(32.8 ; 53.7) \\
17.2 \%(10.2 ; 26.4) \\
17.2 \%(10.2 ; 26.4)\end{array}$ & $\begin{array}{l}\text { I5.6\% (8.8; } 24.7) \\
52.2 \%(41.4 ; 62.9) \\
\text { I8.9\% (II.4; } 28.5) \\
\text { I3.3\% (7.I; 22.1) }\end{array}$ & $\begin{array}{c}31.9 \%(22.5 ; 42.5) \\
48.4 \%(37.7 ; 59.1) \\
14.3 \%(7.8 ; 23.2) \\
5.5 \%(1.8 ; 12.4)\end{array}$ & 0.126 \\
\hline \multicolumn{2}{|l|}{$\begin{array}{l}\text { Alcohol consumption } \\
\text { 16 years } \\
(N=399)\end{array}$} & $20.3 \%(16.4,24.2)$ & $20.0 \%(12.7 ; 29.2)$ & $22.2 \%(14.5 ; 31.7)$ & $15.0 \%(8.7 ; 23.5)$ & $24.0 \%(16.0 ; 33.6)$ & 0.421 \\
\hline \multicolumn{2}{|l|}{$\begin{array}{l}\text { Smoking }^{c} \text { I } 6 \text { years } \\
(N=399)\end{array}$} & $13.3 \%(9.5,16.6)$ & $12.0 \%(6.4 ; 20.0)$ & $15.0 \%(8.7 ; 23.5)$ & $9.1 \%(4.2 ; 16.6)$ & $17.0 \%(10.2 ; 25.8)$ & 0.375 \\
\hline \multicolumn{2}{|c|}{ Age at menarche ${ }^{d}($ year, $N=320)$} & I3.I (I.I) & I3.4(I.0) & $12.9(1.0)$ & |3.0(।.2) & $13.0(1.0)$ & 0.059 \\
\hline \multicolumn{2}{|l|}{$\begin{array}{l}\text { BMI I6 years } \\
\left(\mathrm{kg} / \mathrm{m}^{2}, \mathrm{~N}=399\right)\end{array}$} & $21.0(2.9)$ & $20.3(2.4)$ & $21.0(2.9)$ & $21.2(2.9)$ & $21.7(3.2)$ & $<0.001$ \\
\hline \multicolumn{2}{|l|}{$\begin{array}{l}\text { BMI } 26 \text { years }^{\mathrm{d}} \\
\left(\mathrm{kg} / \mathrm{m}^{2}, \mathrm{~N}=342\right)\end{array}$} & $24.2(7.5)$ & $23.7(4.7)$ & $24.5(5.2)$ & $23.5(3.7)$ & $25.0(12.8)$ & 0.455 \\
\hline \multicolumn{2}{|l|}{$\begin{array}{l}\text { WHR } 16 \text { years }^{d} \\
(N=398)\end{array}$} & $0.77(0.04)$ & $0.77(0.04)$ & $0.77(0.04)$ & $0.77(0.05)$ & $0.77(0.04)$ & 0.781 \\
\hline \multicolumn{2}{|l|}{$\begin{array}{l}\text { WHR } 26 \text { years }^{d} \\
(N=302)\end{array}$} & $0.84(0.08)$ & $0.84(0.08)$ & $0.85(0.10)$ & $0.85(0.08)$ & $0.83(0.08)$ & 0.573 \\
\hline
\end{tabular}

BMI, body mass index; WHR, waist-hip ratio.

aSocio-economic state according to subjects (age 16) mothers, frequency reported, $95 \%$ confidence interval in parentheses.

b Once per month or more, frequency reported, $95 \%$ confidence interval in parentheses.

${ }^{\circ} 2-4$ days per week or more, frequency reported, $95 \%$ confidence interval in parentheses.

'Mean of the variable reported, standard deviation in parentheses.

${ }^{\mathrm{e}} \mathrm{P}$-value for linear trend of continuous variables and for difference between quartiles of category variables. One-way ANOVA for continuous variables and $\chi^{2}$-test for category variables.

\section{AMH and hirsutism}

After exclusion of oral contraceptive users $(n=122)$, women with evidence of hirsutism at age 26 (based on self-reported F\&G score $>7$ ) had significantly higher $\mathrm{AMH}$ levels at age 16 compared with non-hirsute counterparts (Table II). However, in the whole population, including the oral contraceptive users, at age 26 the statistically significant difference disappeared. Similarly, the difference disappeared after exclusion of all those using any hormonal contraceptives (oral contraceptive pill, minipill, hormone intrauterine device, subcutaneous implant or injection) at age 26.

\section{$\mathrm{AMH}$ and PCOS}

Women with PCOS at age 26 ( $n=21,5,3 \%$ of the population) had significantly higher AMH levels at age 16 (Table II). The sensitivity and specificity of the serum concentration of $\mathrm{AMH}$ was evaluated at age 16 for PCOS at age 26 by using cut-off values according to the ROC-curve (Fig. 3). The sensitivity for PCOS at age 26 with a cut-off value for $\mathrm{AMH}$ of $22.5 \mathrm{pmol} / \mathrm{I}(3.15 \mathrm{ng} / \mathrm{ml})$ was $85.7 \%$ and the specificity was $37.5 \%$. When using a cut-off value for AMH of $42.9 \mathrm{pmol} / \mathrm{l}(6.0 \mathrm{l} \mathrm{ng} / \mathrm{ml})$, the sensitivity was $33.3 \%$ and the specificity was $80.0 \%$. Combination of different $\mathrm{AMH}$ and testosterone cut-offs did not significantly improve the accuracy of the test; the best combination was obtained with a cut-off of $22.5 \mathrm{pmol} / \mathrm{I}$ for AMH and $1.7 \mathrm{nmol} / \mathrm{I}$ for T (ROC-curve analysis, Fig. 3), resulting in a sensitivity of $57.1 \%$ and a specificity of $69.9 \%$. An AMH cut-off of $22.5 \mathrm{pmol} / \mathrm{I}$ together with a T cut-off of $2.3 \mathrm{nmol} / \mathrm{I}$ resulted into a sensitivity of $23.8 \%$ and a specificity of $87.6 \%$. An $\mathrm{AMH}$ cut-off of $42.9 \mathrm{pmol} / \mathrm{I}$ combined with a T cut-off of $1.7 \mathrm{nmol} / \mathrm{I}$ resulted into a sensitivity of $23.8 \%$ and specificity of $89.5 \%$, whereas the combination with a T cut-off of $2.3 \mathrm{nmol} / \mathrm{I}$ resulted into a sensitivity of $4.8 \%$ and a specificity of $95.2 \%$.

\section{AMH and metabolic parameters}

In the whole study population, there was a significant but weak correlation between serum AMH levels and BMI at the age of $16(r=0.124, P=$ $0.013)$, but the significance disappeared after adjusting for $T$. At age 16, there was no significant correlation between $\mathrm{AMH}$ levels and metabolic indices (WHR, plasma fasting glucose, serum insulin, HOMA-S, hsCRP, serum total cholesterol, HDL-cholesterol, LDL-cholesterol and triglycerides) after adjusting for testosterone and BMI, except weak correlations in the lowest $T$ quartile (WHR: $r=-0.282, P=0.005$, fasting insulin: $r=0.290, P=0.004$; HOMA-S: $r=-0.221, P=0.033$ ).

\section{Discussion}

In the present study, we evaluated the relationship between AMH and testosterone, oligo- or amenorrhoea and metabolic and cardiovascular markers, and investigated the value of $\mathrm{AMH}$ measurement at the age of 16 in predicting oligo- or amenorrhoea, hirsutism and the diagnosis of PCOS at the age of 26. The results showed that AMH levels associated significantly with T levels and oligo- or amenorrhoea and were a good indicator of oligo- or amenorrhoea in adolescence. A serum AMH levels over $22.5 \mathrm{pmol} / \mathrm{I}$ despite its low specificity and therefore poor value as a diagnostic marker, could be used also to identify the girls at risk for PCOS in early adulthood, and allow early prevention by life style counselling. 


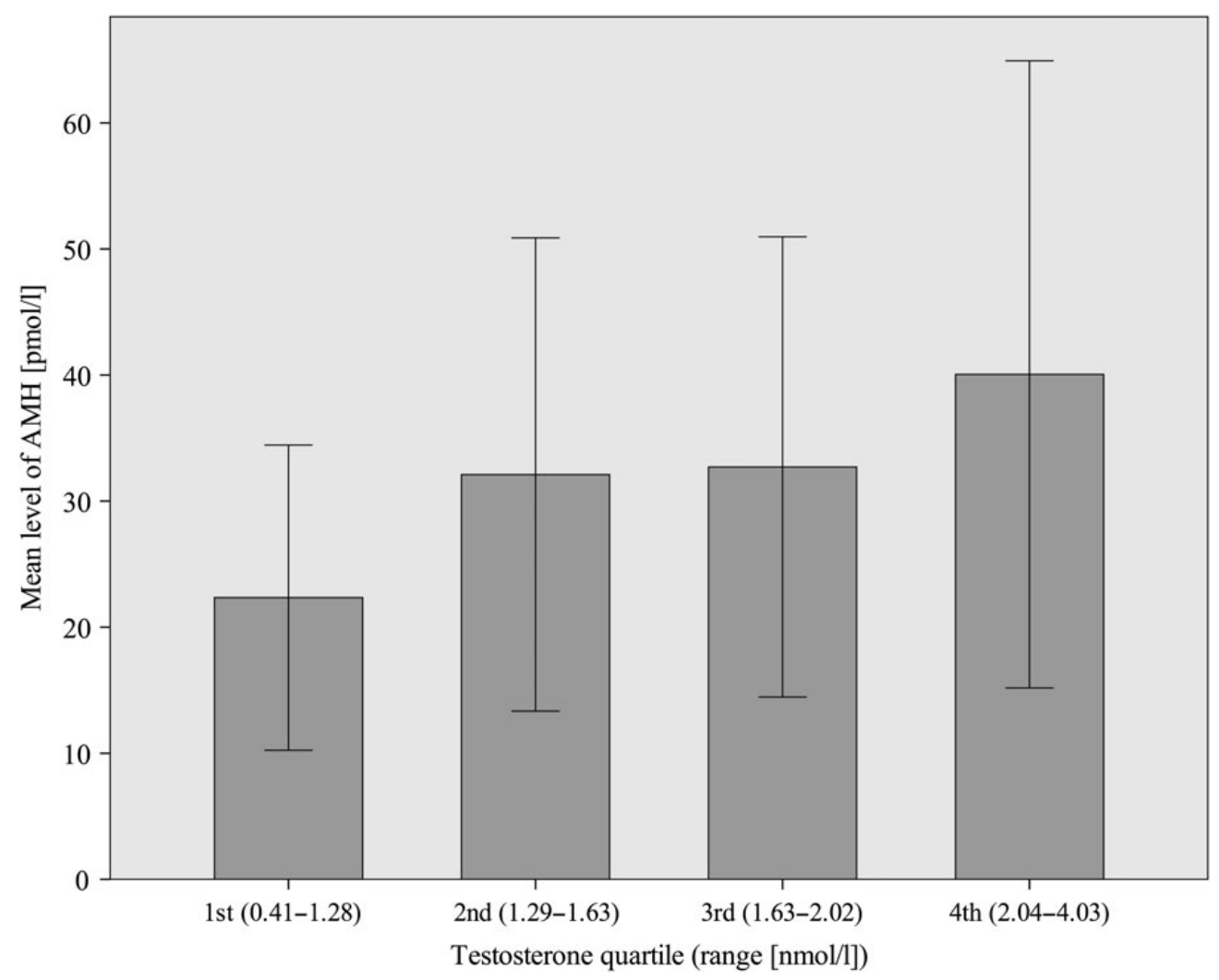

Figure I Mean anti-Müllerian hormone (AMH) levels in different testosterone (T) quartiles. Standard deviations of the means are shown in the bars. $P$-value $<0.00$ I for trend from the lowest towards the highest $T$ quartile.

We previously showed that obesity in adolescence and in adulthood, and also weight gain after adolescence, are associated with selfreported PCOS symptoms in adulthood (Laitinen et al., 2003). Thus, both our previous and present results, and the results from intervention studies treating PCOS (Moran et al., 201 I; Teede et al., 2013) suggest that the prevention of obesity and encouragement of physical exercise are important among girls at risk to prevent the syndrome from developing.

Serum AMH levels at age 16 correlated significantly with T levels in adolescence and with self-reported hirsutism scores at age 26 , which supports recent findings showing a weak correlation with androgens levels and F\&G score (Eilertsen et al., 20I2). In line with the present observations, previous studies have shown that increased $\mathrm{AMH}$ levels are associated with hyperandrogenism and/or oligo- or amenorrhoea in adolescence (Park et al., 20 I0a,b) and adulthood (Laven et al., 2004; Li et al., 20II). In our study, however, the correlation with hirsutism was not significant in the whole study population, probably because of the beneficial effect of the OCs on hirsutism.

The correlation between $\mathrm{AMH}$ and $\mathrm{T}$ levels was the strongest in the highest $T$ quartile, supporting our recent observation that serum $T$ correlates with oligo- or amenorrhoea at age 16 (Pinola et al., 20I2). It is probable that the hyperandrogenic girls more often have polycystic ovaries and thereby higher serum $\mathrm{AMH}$ levels already in adolescence. Unfortunately, we were not able to verify this finding as ultrasound was not performed in this cohort, but previous studies have shown the association both in healthy and in women with PCOS or with PCO only (Pigny et al., 2003; Hart et al., 2010a,b).

To our knowledge, this is the first longitudinal follow-up study investigating the possible value of AMH as a marker for the development of PCOS later in early adulthood. Interestingly, the highest T quartile was the only one in which $\mathrm{AMH}$ at age 16 was significantly higher in women who experienced oligo- or amenorrhoea at age 26 compared with women with a normal menstrual cycle. Based on the present and previous results (Pigny etal., 2003; Hart etal., 20 I0a,b), we suggest that the girls with irregular cycles and higher testosterone levels at age 16 have a higher antral follicle count and AMH levels and are therefore likely to fulfil the criteria for PCOS later in life. In line with this hypothesis, women with PCOS (either diagnosed or self-reported symptoms according to the questionnaire) at age 26 had higher serum AMH levels in adolescence compared with healthy women and serum AMH levels over $22.5 \mathrm{pmol} / \mathrm{I}$ could identify with a sensitivity of $85.7 \%$ the adolescent girls at risk for PCOS in early adulthood. The specificity of the test remained weak but improved substantially when using a cut-off of $42.8 \mathrm{pmol} / \mathrm{I}$. Similarly, the results of previous studies have indicated that $\mathrm{AMH}$ alone may not be good enough as a single screening tool for PCOS. In the present study, however, the combination of $\mathrm{AMH}$ and $\mathrm{T}$ did not improve the accuracy of the test, in line with some (Casadei et al., 2013), but not all studies (Eilertsen et al., 2012) in which the power of AMH to diagnose PCOS increased substantially when combined with the other diagnostic criteria of PCOS. The girls with oligo- or amenorrhoea at age 16 and PCOS or hirsutism alone at 


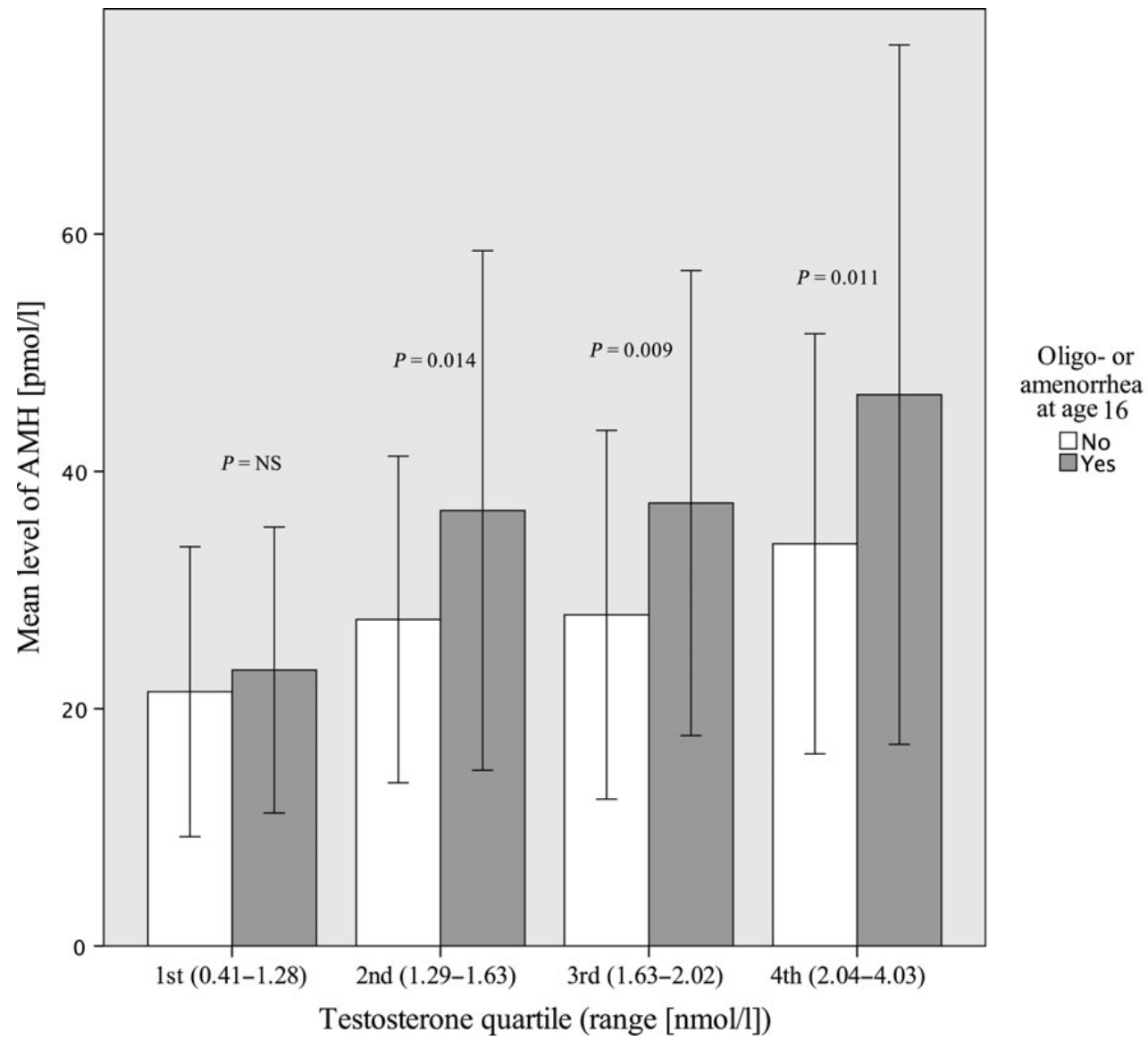

Figure 2 Mean anti-Müllerian hormone (AMH) levels, in the subjects with oligo- or amenorrhoea (grey) and in the subjects with normal menstrual cycles (white), in testosterone quartiles, at age 16. Standard deviations of the means are shown in the bars. $P$-value for the difference between girls with oligo- or amenorrhoea and girls with normal menstrual cycle in each T quartile.

Table II Anti-Müllerian hormone (AMH) concentrations at age 16 in women with hirsutism or polycystic ovary syndrome (PCOS) at age 26.

\begin{tabular}{|c|c|c|c|}
\hline & & $\begin{array}{l}\text { Mean AMH } \\
\text { concentration } \\
(\mathrm{pmol} / \mathrm{l})^{\mathrm{a}}\end{array}$ & $P$-value \\
\hline Hirsutism at age $26^{\mathrm{b}}$ (Ferriman \& Gallwey score $\left.>7\right)^{\mathrm{c}}$ & $\begin{array}{l}\text { Yes }(n=34) \\
\text { I3.2(II.8; I4.6) } \\
\text { No }(n=17 \mid) \\
4.4(3.0 ; 5.9)^{\mathrm{d}}\end{array}$ & $\begin{array}{l}31.4(27.1 ; 36.5)^{\mathrm{e}} \\
25.8(23.3 ; 28.6)^{\mathrm{e}}\end{array}$ & 0.036 \\
\hline PCOS at age $26^{f}$ & $\begin{array}{l}\text { Yes }(n=21) \\
\text { No }(n=209)\end{array}$ & $\begin{array}{l}38.2(27.8 ; 48.5) \\
30.2(27.9 ; 32.5)\end{array}$ & 0.044 \\
\hline
\end{tabular}

${ }^{\mathrm{a}} 95 \%$ confidence interval in parentheses.

${ }^{\mathrm{b}}$ According to modified Ferriman \& Gallway score $(>7)$.

73 subjects missing from the analysis due to the non-response to some items, 122 oral contraceptive users excluded.

dMean Ferriman \& Gallway score, $95 \%$ confidence interval in parentheses.

${ }^{e}$ Geometric mean for AMH.

f 170 subjects missing from the analysis due to the non-response to some items.

age 26, however, had higher levels of $\mathrm{AMH}$ already at age 16, suggesting that the association between elevated $\mathrm{AMH}$ and symptoms of PCOS in adolescence persists also in early adulthood. Using a high enough cut-off value could help to distinguish most of the hyperandrogenic adolescents at risk for PCOS, but a routine use of this test in clinical practice cannot at present be recommended. 


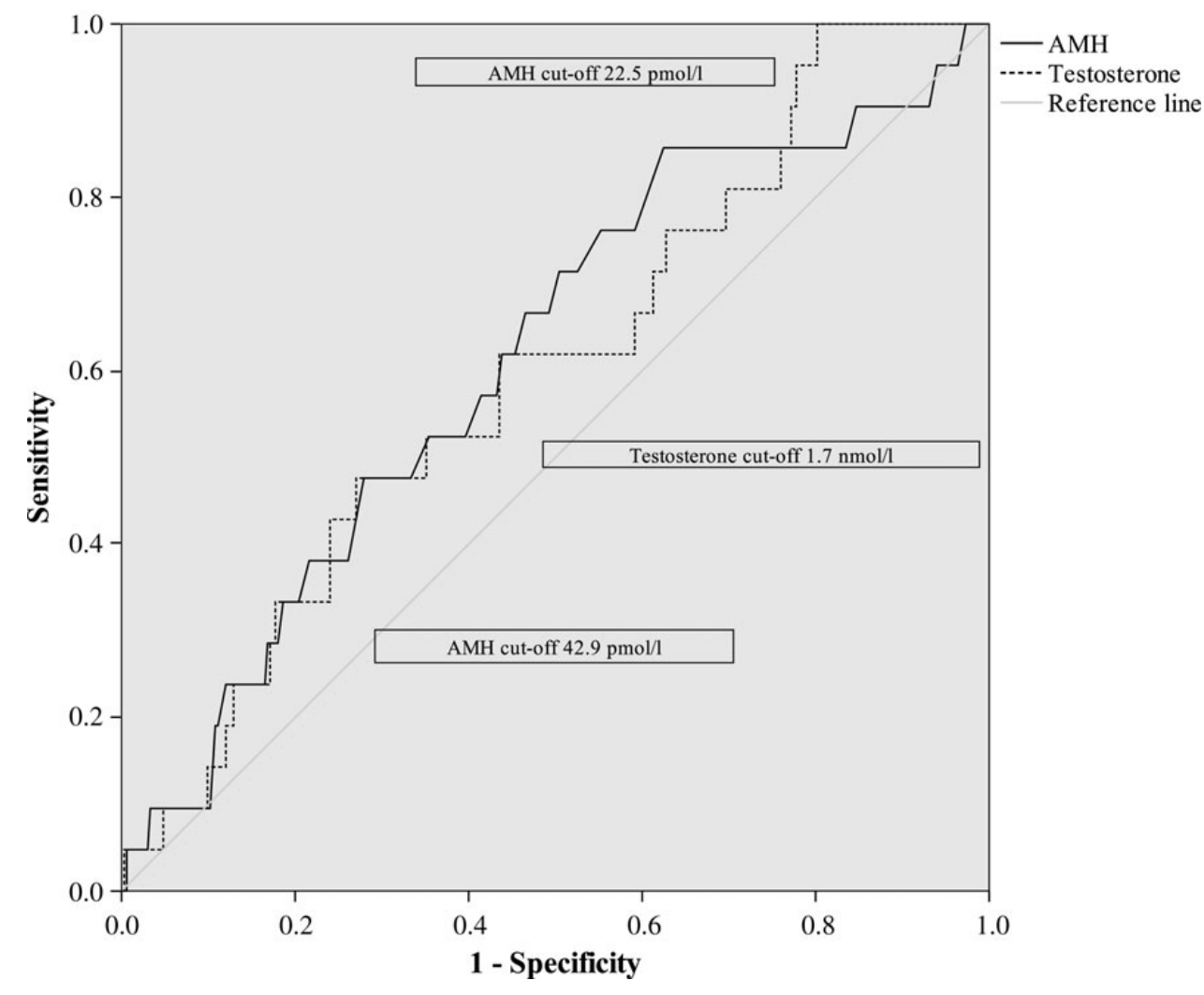

Figure 3 ROC curves of testosterone and AMH for PCOS. Cut-off points with the best sensitivity and specificity used in the analyses are shown in the figure.

We did not find any significant association between $\mathrm{AMH}$ and metabolic indices in the whole study population at age 16 , which is in agreement with a recent report of a different European population (Anderson et al., 20I3). This result indicates that $\mathrm{AMH}$, despite its association with testosterone (Piltonen et al., 2005; Kristensen et al., 20I2), is a poor marker of metabolic risks in adolescence. In contrast, in other studies (Nardo et al., 2009; Skalba et al., 20II), AMH associated positively with insulin, HOMA-IR and negatively with HDL, and in one study (Skalba et al., 20I I) also positively with total cholesterol and LDL. These studies, however, were performed in older subjects in early adulthood or later, in an age range from 18 to $4 \mathrm{I}$. It may be that metabolic risks develop later in life and could not be identified in our study performed in adolescence.

An important pitfall is that $\mathrm{AMH}$ assays lack an agreed international standard and therefore the concentrations and cut-off points are method dependent. Importantly, however, in this study all the measurements were made simultaneously using the same AMH assay. Other limitations of this study are that we did not obtain blood samples from the subjects at the age of 26 and that AMH was measured in a subset of the whole cohort. Last, the diagnosis of PCOS at age 26 was based on a questionnaire, but we have previously demonstrated in a similar cohort at age 31 (the Northern Finland Birth Cohort 1966) that self-reported oligo- or amenorrhoea and hirsutism can identify most women with the typical endocrine and metabolic profile of PCOS (Taponen et al., 2003, 2004). Moreover, women with both symptoms fulfilled the Rotterdam criteria for the definition of PCOS (Rotterdam ESHRE/ASRMSponsored PCOS consensus workshop group, 2004).

\section{Conclusion}

Serum AMH levels associate significantly with T levels and oligo- or amenorrhoea at age 16 and are a good indicator of oligo- or amenorrhoea in adolescence. Using a high enough cut-off value of $\mathrm{AMH}$ to predict which adolescents are likely to develop PCOS in adulthood, despite its low specificity, could help to manage the condition from an early age with a good sensitivity. However, it is not an ideal diagnostic marker and its routine use in clinical practice cannot at present be recommended. Furthermore, $\mathrm{AMH}$ is not a good marker for cardiovascular risk factors in adolescence.

\section{Authors' roles}

P.P.: study design, execution, analysis, manuscript drafting and critical discussion. L.C.M.-P.: study design, execution, manuscript drafting and critical discussion. A.B.: execution and analysis. K.P.: execution and analysis. A.R.: study design and critical discussion. M.-R.J.: study design and critical discussion. S.F.: study design, manuscript drafting and critical discussion. J.S.T.: study design, manuscript drafting and critical discussion. H.L.: study design, manuscript drafting and critical discussion.

\section{Funding}

The study was funded by grants from the Wellcome Trust (089549/Z/ 09/Z) to H.L., S.F. and M.-R.J. and from Oulu University Hospital Research Funds, Sigrid Juselius Foundation and the Academy of Finland 
to J.S.T., P.P. and L.C.M.-P. Funding to pay the Open Access publication charges for this article was provided by The Wellcome Trust.

\section{Conflict of interest}

None declared.

\section{References}

Anderson EL, Fraser A, McNally W, Sattar N, Lashen H, Fleming R, Nelson SM, Lawlor DA. Anti-mullerian hormone is not associated with cardiometabolic risk factors in adolescent females. PLoS One 2013; 8:e64510.

Casadei L, Madrigale A, Puca F, Manicuti C, Emidi E, Piccione E, Dewailly D. The role of serum anti-Mullerian hormone $(\mathrm{AMH})$ in the hormonal diagnosis of polycystic ovary syndrome. Gynecol Endocrinol 20I 3;29:545-550.

Crisosto N, Sir-Petermann T, Greiner M, Maliqueo M, Moreno M, Aedo P, Lara HE. Testosterone-induced downregulation of anti-Mullerian hormone expression in granulosa cells from small bovine follicles. Endocrine 2009;36:339-345.

Dewailly D, Gronier H, Poncelet E, Robin G, Leroy M, Pigny P, Duhamel A, Catteau-Jonard S. Diagnosis of polycystic ovary syndrome (PCOS): revisiting the threshold values of follicle count on ultrasound and of the serum AMH level for the definition of polycystic ovaries. Hum Reprod 201।;26:3123-3129.

Durlinger AL, Kramer P, Karels B, de Jong FH, Uilenbroek JT, Grootegoed JA, Themmen AP. Control of primordial follicle recruitment by anti-Mullerian hormone in the mouse ovary. Endocrinology 1999; I 40:5789-5796.

Durlinger AL, Visser JA, Themmen AP. Regulation of ovarian function: the role of anti-Mullerian hormone. Reproduction 2002; I 24:60 I-609.

Ehrmann DA. Polycystic ovary syndrome. N Engl J Med 2005; 352: $1223-1236$.

Eilertsen TB, Vanky E, Carlsen SM. Anti-Mullerian hormone in the diagnosis of polycystic ovary syndrome: can morphologic description be replaced? Hum Reprod 2012;27:2494-2502.

Franks S. Polycystic ovary syndrome. N Engl J Med 1995;333:853-86I.

Gardner MJ, Altman DG. Statistics with Confidence. London, UK: BMJ Publishing, 1989.

Gruijters MJ, Visser JA, Durlinger AL, Themmen AP. Anti-Mullerian hormone and its role in ovarian function. Mol Cell Endocrinol 2003;2 I I:85-90.

Hart R, Doherty DA, Norman RJ, Franks S, Dickinson JE, Hickey M, Sloboda DM. Serum antimullerian hormone $(A M H)$ levels are elevated in adolescent girls with polycystic ovaries and the polycystic ovarian syndrome (PCOS). Fertil Steril 2010a;94: I I 8- I 121.

Hart R, Doherty DA, Norman RJ, Franks S, Dickinson JE, Hickey M, Sloboda DM. Serum antimullerian hormone $(A M H)$ levels are elevated in adolescent girls with polycystic ovaries and the polycystic ovarian syndrome (PCOS). Fertil Steril 20 I0b;94: I I I8- I I2I.

lliodromiti S, Kelsey TW, Anderson RA, Nelson SM. Can anti-Mullerian hormone predict the diagnosis of polycystic ovary syndrome? A systematic review and meta-analysis of extracted data. J Clin Endocrinol Metab 20I3;98:3332-3340.

Kristensen SL, Ramlau-Hansen CH, Andersen CY, Ernst E, Olsen SF, Bonde JP, Vested A, Toft G. The association between circulating levels of antimullerian hormone and follicle number, androgens, and menstrual cycle characteristics in young women. Fertil Steril 20 I2;97:779-785.

Kuiri-Hänninen T, Kallio S, Seuri R, Tyrväinen E, Liakka A, Tapanainen J, Ulla Sankilampi U, Dunkel L. Postnatal developmental changes in the pituitary-ovarian axis in preterm and term infant girls. J Clin Endocrinol Metab 20I I;96:3432-3439.
Kumar A, Kalra B, Patel A, McDavid L, Roudebush WE. Development of a second generation anti-Mullerian hormone (AMH) ELISA. J Immunol Methods 2010;362:5I-59.

Laitinen J, Taponen S, Martikainen H, Pouta A, Millwood I, Hartikainen AL, Ruokonen A, Sovio U, McCarthy MI, Franks S et al. Body size from birth to adulthood as a predictor of self-reported polycystic ovary syndrome symptoms. Int J Obes Relat Metab Disord 2003;27:710-715.

Laven JS, Mulders AG, Visser JA, Themmen AP, De Jong FH, Fauser BC. Anti-Mullerian hormone serum concentrations in normoovulatory and anovulatory women of reproductive age. J Clin Endocrinol Metab 2004; 89:318-323.

Legro RS. Polycystic ovary syndrome. Long term sequelae and management. Minerva Ginecol 2002;54:97- I 14.

Li HW, Anderson RA, Yeung WS, Ho PC, Ng EH. Evaluation of serum antimullerian hormone and inhibin $\mathrm{B}$ concentrations in the differential diagnosis of secondary oligoamenorrhea. Fertil Steril 20 I I;96:774-779.

Lin YH, Chiu WC, Wu CH, Tzeng CR, Hsu CS, Hsu MI. Antimullerian hormone and polycystic ovary syndrome. Fertil Steril 20 I ; 96:230-235.

Moran LJ, Hutchison SK, Norman RJ, Teede HJ. Lifestyle changes in women with polycystic ovary syndrome. Cochrane Database Syst Rev 201I; 7:CD007506.

Nardo LG, Yates AP, Roberts SA, Pemberton P, Laing I. The relationships between $\mathrm{AMH}$, androgens, insulin resistance and basal ovarian follicular status in non-obese subfertile women with and without polycystic ovary syndrome. Hum Reprod 2009;24:2917-2923.

Nisenblat V, Norman RJ. Androgens and polycystic ovary syndrome. Curr Opin Endocrinol Diabetes Obes 2009; 16:224-231.

Park AS, Lawson MA, Chuan SS, Oberfield SE, Hoeger KM, Witchel SF, Chang RJ. Serum anti-mullerian hormone concentrations are elevated in oligomenorrheic girls without evidence of hyperandrogenism. J Clin Endocrinol Metab 2010a;95: 1786- 1792.

Park HT, Cho GJ, Ahn KH, Shin JH, Kim YT, Hur JY, Kim SH, Lee KW, Kim T. Association of insulin resistance with anti-Mullerian hormone levels in women without polycystic ovary syndrome (PCOS). Clin Endocrinol (Oxf) 2010b; 72:26-31.

Pigny P, Merlen E, Robert Y, Cortet-Rudelli C, Decanter C, Jonard S, Dewailly D. Elevated serum level of anti-mullerian hormone in patients with polycystic ovary syndrome: relationship to the ovarian follicle excess and to the follicular arrest. J Clin Endocrinol Metab 2003;88:5957-5962.

Pigny P, Jonard S, Robert Y, Dewailly D. Serum anti-Mullerian hormone as a surrogate for antral follicle count for definition of the polycystic ovary syndrome. J Clin Endocrinol Metab 2006;9 1:94I-945.

Piltonen T, Morin-Papunen L, Koivunen R, Perheentupa A, Ruokonen A, Tapanainen JS. Serum anti-Mullerian hormone levels remain high until late reproductive age and decrease during metformin therapy in women with polycystic ovary syndrome. Hum Reprod 2005;20: I820- 1826.

Pinola P, Lashen H, Bloigu A, Puukka K, Ulmanen M, Ruokonen A, Martikainen $\mathrm{H}$, Pouta A, Franks S, Hartikainen AL et al. Menstrual disorders in adolescence: a marker for hyperandrogenaemia and increased metabolic risks in later life? Finnish general population-based birth cohort study. Hum Reprod 2012;27:3279-3286.

Rajpert-De Meyts E, Jorgensen N, Graem N, Muller J, Cate RL, Skakkebaek NE. Expression of anti-Mullerian hormone during normal and pathological gonadal development: association with differentiation of Sertoli and granulosa cells. J Clin Endocrinol Metab 1999;84:3836-3844.

Rotterdam ESHRE/ASRM-Sponsored PCOS consensus workshop group. Revised 2003 consensus on diagnostic criteria and long-term health risks related to polycystic ovary syndrome (PCOS). Hum Reprod 2004; 19:41-47.

Skalba P, Cygal A, Madej P, Dabkowska-Huc A, Sikora J, Martirosian G, Romanik M, Olszanecka-Glinianowicz M. Is the plasma anti-Mullerian hormone $(\mathrm{AMH})$ level associated with body weight and metabolic, and 
hormonal disturbances in women with and without polycystic ovary syndrome? Eur J Obstet Gynecol Reprod Biol 20 I I; I 58:254-259.

Solomon CG, Hu FB, Dunaif A, Rich-Edwards JE, Stampfer MJ, Willett WC, Speizer FE, Manson JE. Menstrual cycle irregularity and risk for future cardiovascular disease. J Clin Endocrinol Metab 2002;87:2013-20I7.

Stubbs SA, Hardy K, Da Silva-Buttkus P, Stark J, Webber LJ, Flanagan AM, Themmen AP, Visser JA, Groome NP, Franks S. Anti-mullerian hormone protein expression is reduced during the initial stages of follicle development in human polycystic ovaries. J Clin Endocrinol Metab 2005; 90:5536-5543.

Taponen S, Martikainen H, Jarvelin MR, Laitinen J, Pouta A, Hartikainen AL, Sovio U, McCarthy MI, Franks S, Ruokonen A. Hormonal profile of women with self-reported symptoms of oligomenorrhea and/or hirsutism: Northern Finland birth cohort 1966 study. J Clin Endocrinol Metab 2003; 88: $|4|-\mid 47$.

Taponen S, Ahonkallio S, Martikainen H, Koivunen R, Ruokonen A, Sovio U, Hartikainen AL, Pouta A, Laitinen J, King V et al. Prevalence of polycystic ovaries in women with self-reported symptoms of oligomenorrhoea and/or hirsutism: Northern Finland Birth Cohort 1966 Study. Hum Reprod 2004; 19: 1083- 1088.

Teede HJ, Joham AE, Paul E, Moran LJ, Loxton D, Jolley D, Lombard C. Longitudinal weight gain in women identified with polycystic ovary syndrome: results of an observational study in young women. Obesity (Silver Spring) 2013;21:1526- 1532.

Vigier B, Picard JY, Tran D, Legeai L, Josso N. Production of anti-Mullerian hormone: another homology between Sertoli and granulosa cells. Endocrinology 1984; I 14:1315-1320.

Wallace AM, Faye SA, Fleming R, Nelson SM. A multicentre evaluation of the new Beckman Coulter anti-Mullerian hormone immunoassay (AMH Gen II). Ann Clin Biochem 20I I;48:370-373.

Weenen C, Laven JS, Von Bergh AR, Cranfield M, Groome NP, Visser JA, Kramer P, Fauser BC, Themmen AP. Anti-Mullerian hormone expression pattern in the human ovary: potential implications for initial and cyclic follicle recruitment. Mol Hum Reprod 2004; 1 0:77-83. 